\title{
А. А. Никоненко
}

\section{Особенности локализации и варианта хирургического лечения аневризм непарных висцеральных ветвей аорты}

\author{
Запорожский государственный медицинский университет
}

Ключевье слова: аневризма непарньх висиеральных ветвей, мультисрезовая спиральная компьютерная томография, хирургическое лечение.

Аневризмы непарных висцеральных ветвей аорты диагностируют случайно при обследовании по поводу другого заболевания органов брюшной полости либо при разрыве аневризмы. В настоящее время доступны такие методы лечения, как открытая операция и эндоваскулярное вмешательство. Проведен анализ данных обследований и результатов хирургического лечения 30 больных. Методом мультисрезовой спиральной компьютерной томографии и ангиографии установлена наиболее частая локализация аневризм - бассейны чревного ствола $(73,3 \%)$ и верхней брыжеечной артерии (23,3\%). Открытых хирургических вмешательств всего выполнено $45,4 \%$, эндоваскулярных $-54,5 \%$. На основании анализа результатов лечения отдается предпочтение эндоваскулярному вмешательству.

\section{Особливості локалізації та варіанта хірургічного лікування аневризм непарних вісцеральних гілок аорти}

\section{А. О. Никоненко}

Аневризми непарних вісцеральних гілок аорти діагностують випадково протягом обстеження з приводу іншого захворювання органів черевної порожнини або при розриві аневризми. Нині доступні такі методи лікування, як відкрита операція й ендоваскулярне втручання. Здійснили аналіз даних обстежень і результатів хірургічного лікування 30 хворих. Методом мультизрізової спіральної комп'ютерної томографії та ангіографії встановили найбільш часту локалізацію аневризм - басейни черевного стовбура (73,3\%) і верхньої брижової артерії (23,3\%). Відкриті хірургічні втручання виконали у 45,4\% випадків, ендоваскулярні втручання - 54,5\%. На підставі аналізу результатів лікування надається перевага ендоваскулярним втручанням.

Ключові слова: аневризма непарних вісиеральних гілок, мультизрізова спіральна комп 'ютерна томографія, хірургічне лікування.

Запорізький медичний жсурнал. - 2014. - №2 (83). - С. 29-31

\section{Features of localization and type of surgical treatment of aneurysms of unpaired visceral aortal branches.}

\section{A. A. Nykonenko}

Aneurysms of unpaired visceral aortal branches usually diagnosed incidentally during abdominal examination, or in case of rupture of the aneurysm. Currently open surgery or endovascular intervention can be proposed as method of treatment. Results of the physical exam and surgical treatment of 30 patients were analyzed. The most frequent localization of the aneurysm (celiac trunk $(73,3 \%)$ and superior mesenteric artery $(23,3 \%))$ was detected by multi-slice spiral computed tomography. Open surgical procedures were done just for $45,4 \%$, endovascular interventions $-54,5 \%$. Analysis of treatment outcomes showed benefits of the endovascular intervention.

Key words: aneurysm of unpaired visceral branches, MSCT, surgical treatment.

Zaporozhye medical journal 2014; №2 (83): 29-31

$\mathrm{B}^{\mathrm{s}}$ большинстве случаев аневризмы непарных висцеральных ветвей аорты (АНВВ) диагностируют случайно при обследовании по поводу другого заболевания органов брюшной полости либо при разрыве аневризмы [1]. В последние годы, благодаря частому применению ультразвукового дуплексного сканирования (УЗДС), мультисрезовой спиральной компьютерной томографии (МСКТ) и магнитно-резонансной томографии (МРТ) при различных заболеваниях органов брюшной полости, стали диагностировать бессимптомно протекающие аневризмы [2].

До настоящего времени из-за редкости АНВВ в специализированной литературе нет четко обоснованного подхода к показаниям и выбору метода лечения [3].

Хирургическое лечение заключается в легировании артерии и резекции аневризмы, которые выполняют в случае, если имеется достаточный коллатеральный кровоток; если есть опасность развития ишемии органа, который питает аневризмонесущая артерия, нужно проводить реконструктивную операцию $[1,4]$. Реконструктивная операция обязательна при аневризмах печеночной и верхней брыжеечной артерии, так как рассчитывать на хороший коллатеральный кровоток вряд ли возможно [5].
Рентгеноэндоваскулярное лечение в последние годы становится методом выбора для большинства больных AНВВ. Существует несколько способов эндоваскулярного выключения аневризмы из кровотока: эмболизация артерии или заполнение полости аневризмы спиралями и эндопротезирование [6,7].

Таким образом, выбор тактики лечения зависит от локализации процесса.

\section{Цель работы}

Изучить локализации аневризм непарных висцеральных ветвейаорты и на основании анализа результатов хирургического лечения определить оптимальный вариант лечения.

\section{Пациенты и методы исследования}

Проведен анализ данных обследований и результатов хирургического лечения 30 больных АНВВ. Средний возраст пациентов составил 52,2 $\pm 15,2$ лет (от 23 лет до 76). Преобладали пациенты мужского пола - 20(66,7\%). Всем больным выполнена ангиография или мультисрезовая спиральная компьютерная томография (МСКТ). Ангиография выполнена на аппарате «Siemens Axiom Artis MP» (Германия, $2005)$ в Запорожской областной клинической больнице и в 
Национальном институте хирургии и трансплантологии им. A.A. Шалимова НАMН Украины - «Siemens MS Plus» (Германия, 2000). Стандартно ангиографическое исследование проводили в передне-задней проекции, а при необходимости дополняли как селективной установкой катетера, так и полипроекционной съемкой. После цифровой обработки изображение сохранялось на жестком диске компьютера для возможности детального анализа полученных данных. МСКТ выполнена по стандартной методике на 4-детекторном аппарате Toshiba Asteion и 64x-детекторном - GE Optima 660, оснащенных автоматическим инъектором. Обработку полученных изображений и их реконструкцию в 3 проекциях выполняли на рабочей станции Vitrea. На 64x-срезовом компьютерном томографе: конфигурация детекторов $64 \mathrm{x}$ толщина среза - 0,6 мм, питч - 0,984:1. Полученные аксиальные срезы обрабатывали на рабочей станции AW Volume Share 5. Вводили от 80 до 100 мл йодсодержащего контрастного вещества (Юнипак 350, Unique или Ультравист 370, Bayer-Shering) со скоростью 3,5 мл/с. Использовали автоматическую болюс-трекинг систему для получения артериальной фазы (при достижении плотности контрастного вещества в брюшной аорте $180 \mathrm{Hu}$, сканирование начиналось через 8-10 секунд). Методом ангиографии обследовали 17 больных. МСКТ выполнена 14 больным. Хирургическая коррекция проведена 22 больным (73,3\%).

\section{Результаты и их обсуждение}

На основании проведенного МСКТ и ангиографии определены анатомические уровни локализации АНВВ. Основные уровни поражения бассейна чревного ствола (ЧС), верхней брыжеечной артерии (ВБА) и нижней брыжеечной артерии (НБА) представлены на рис. 1. Локализация поражения в бассейне ЧС $(\mathrm{n}=22)$ : непосредственно в ЧС обнаружено $5(16,7 \%)$ аневризм, в селезеночной артерии - $13(43,3 \%)$, желудочной артерии - $2(6,7 \%)$, верхней панкреатодуоденальной артерии - 1 (3,3\%), правой печеночной артерии $-1(3,3 \%)$. Средний возраст пациентов с поражением в бассейне ЧС - 51,5 $\pm 15,4$ года, преобладали мужчины - 14 больных $(63,6 \%)$.

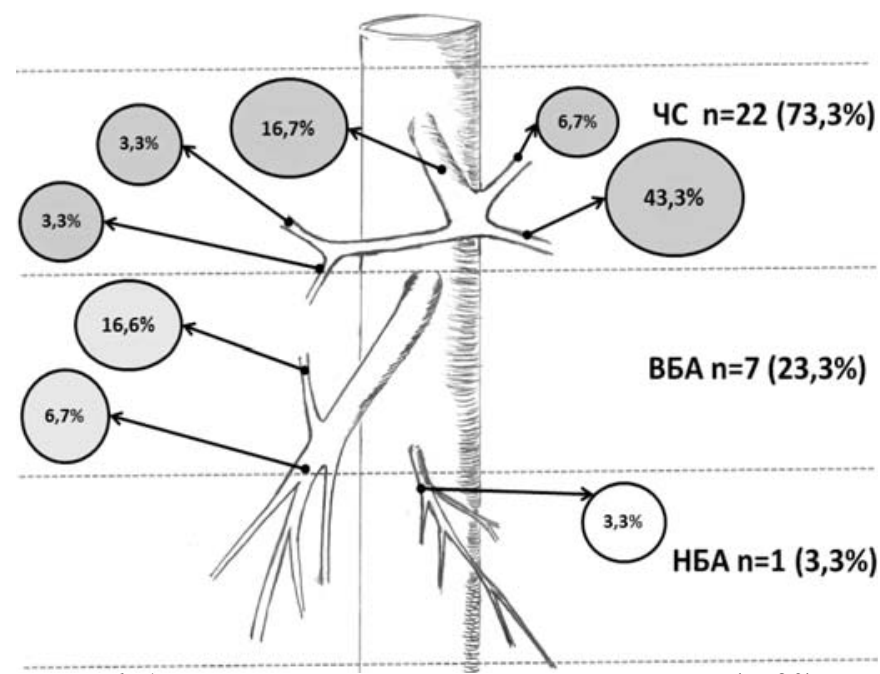

Puc. 1. Анатомическая локализация аневризм $\mathrm{HBB}(\mathrm{n}=30)$.

Локализация поражения ВБА (n=7) в 5 (16,6 \%) случаях была в нижней панкреатодуоденальной артерии (из них у 3 больных обнаружена окклюзия чревного ствола). В 2 (6,7 \%) случаях аневризма локализовалась в ветвях ВБА третьего порядка. Возраст пациентов аневризмой ВБА - 51 (38-68) год, преобладали мужчины - 5 (71,4\%). Локализация аневризмы НБА $(3,3 \%)$ - в начальном отделе артерии, возраст мужчины - 71 год.

Таким образом, наиболее часто обнаруживали аневризмы в бассейне ЧС - аневризма селезеночной артерии (43,3\%), следующие по частоте - аневризма ЧС $(16,7 \%)$, аневризма нижней панкреатодуоденальной артерии (16,6\%). Далее по частоте - бассейн ВБА и НБА.

Проведен анализ данных диаметра аневризм относительно анатомической локализации (табл. 1). В анализируемой группе достоверного отличия диаметра в зависимости от локализации аневризмы не отметили.

Таблица 1

Максимальный диаметр АНВВ

в зависимости от локализации процесса $(n=30)$

\begin{tabular}{|c|c|c|}
\hline $\begin{array}{c}\text { Анатомическая } \\
\text { локализация }\end{array}$ & Абс, \% & $\begin{array}{c}\text { Диаметр, } \\
\text { М (25\%-75\%)мм }\end{array}$ \\
\hline Бассейн ЧС & $22(73,3 \%)$ & $30(18-60)$ \\
\hline Селезеночная артерия & $13(43,3 \%)$ & $30(20-60)$ \\
\hline чС & $5(16,7 \%)$ & $30(18-35)$ \\
\hline Желудочная артерия & $2(6,7 \%)$ & $29,5(21-38)$ \\
\hline $\begin{array}{c}\text { Верхняя панкреатодуоденальная } \\
\text { артерия }\end{array}$ & $1(3,3 \%)$ & 38 \\
\hline Правая печеночная артерия & $1(3,3 \%)$ & 38 \\
\hline Бассейн ВБА & $7(23,3 \%)$ & $30(15-66)$ \\
\hline Нижняя панкреатодуоденальная \\
артерия & $5(16,6 \%)$ & $30(18-37)$ \\
\hline Ветви ВБА третьего порядка & $2(6,7 \%)$ & $40,5(15-66)$ \\
\hline НБА & $1(3,3 \%)$ & 18 \\
\hline
\end{tabular}

Обращает внимание возникновение аневризм в бассейне ВБА в коллатерале между ВБА и бассейном чревного ствола у 3 больных на фоне окклюзии ЧС и сформировавшихся компенсаторных коллатералей. Возникновение аневризм в коллатералях, по всей видимости, связано с дополнительной нагрузкой на эти артерии, изначально не предназначенные для выполнения такой гемодинамической нагрузки.

Таблииа 2

Вид и количество хирургических вмешательств при АНBВ $(\mathrm{n}=22)$

\begin{tabular}{|c|c|c|}
\hline $\begin{array}{c}\text { Анатомическая } \\
\text { локализация }\end{array}$ & Вид операции & Абс., \% \\
\hline \multirow{2}{*}{$\begin{array}{c}\text { Бассейн } \\
\text { чревного } \\
\text { ствола }\end{array}$} & Открытая & $6(27,3 \%)$ \\
\hline & Эндоваскулярная & $9(40,9 \%)$ \\
\hline \multirow{2}{*}{ Бассейн ВБА } & Открытая & $3(13,6 \%)$ \\
\hline & Эндоваскулярная & $3(13,6 \%)$ \\
\hline \multirow{2}{*}{ НБА } & Открытая & $1(4,5 \%)$ \\
\hline & Эндоваскулярная & $0(0 \%)$ \\
\hline \multicolumn{2}{|c|}{ Всего операций } & $22(100 \%)$ \\
\hline \multicolumn{2}{|c|}{ Эндоваскулярные } & $12(54,5 \%)$ \\
\hline \multicolumn{2}{|c|}{ Открытые } & $10(45,4 \%)$ \\
\hline
\end{tabular}

Тактика хирургического вмешательства базировалась на локализации процесса. В таблице 2 представлены варианты выполненного хирургического лечения.

Все эндоваскулярные вмешательства в анализируемой группе больных заключались в эмболизации полости аневризмы. Для этого выполняли селективную ангиогра- 
фию аневризм-зависимой артерии, в полость аневризмы вводили спирали. В дальнейшем проводили контрольную ангиографию или МСКТ для контроля за тромбированием полости аневризмы.

Открытые хирургические вмешательства (10/100\%) в большинстве случаев заключались в лигировании артерии и резекции аневризмы -8 (80\%), резекции аневризмы и протезировании - 2 (20\%).

Осложнения интраоперационного периода были только при открытых вмешательствах - 3 (13,6\%). Во всех случаях отметили повышенную кровопотерю (более 1000 мл) по ходу выполнения доступа к аневризме. Хирургическое лечение заключается в лигировании артерии и резекции аневризмы, что выполняли в случае, если имеется достаточный коллатеральный кровоток. Если же есть опасность развития ишемии органа, который питает аневризмонесущая артерия, нужно выполнять реконструктивную операцию $[1,4]$. Реконструктивная операция обязательна при аневризмах печеночной (бассейн ЧС) и ВБА, так как рассчитывать на хороший коллатеральный кровоток вряд ли возможно $[5,8]$.

Рентгеноэндоваскулярное лечение в последние годы становится методом выбора для большинства больных AHBB, существует несколько способов эндоваскулярного выключения аневризмы из кровотока: эмболизация артерии или заполнение полости аневризмы спиралями и эндопротезирование [6,7].

В настоящее время благодаря бурному развитию эндоваскулярной хирургии появились новые методы хирургической коррекции АНВВ: эндоваскулярная эмболизация полости аневризмы, эндоваскулярное протезирование, стентирование.

Для определения тактики хирургического лечения необходимо учитывать локализацию аневризмы, диаметр, наличие коллатерального кровообращения, определиться с необходимостью сохранения кровотока по аневризмо-

\section{Список литературы}

1. Аневризмы висцеральных и почечных артерий: диагностика и лечение / [Ф.Ф. Хамидов, М.Д. Дибиров, С.А. Терещенко] // Хирургия. - 2013. - № 12. - С. 85-88.

2. Pancreatoduodenalarteryaneurysmresultingfrommedianarcuatelig amentcompressionsuccessfullytreatedwithlaparoscopic ligament section / Y.L. Hiramatsu, T. Sakaguchi, T. Kawabata [et al.] // Asian. J. Endosc. Surg. - 2014. - Vol. 7(1). - P. 75-78.

3. Treatment of visceral artery aneurysm: description of a retrospective series of 42 aneurysm in 34 patients / C. Sessa, G. Tinella, P. Porcu [et al.] // Ann. Vasc. Surg. - 2004. - Vol. 18. - P. 695-703.

4. Janzen R.M. Visceral artery aneurysm / R.M. Janzen, W.T. Simpson // C. J. S. - 2004. -Vol. 43. - № 4. - P. 301-302.

5. Visceral artery aneurysms: experience in a tertiary-care center/A Hossain, E.D. Reis, S.P. Dave [et al.] // Am. Surg. - 2001. - Vol. 67. - № 5. - P. 432-437.

6. Endovascular treatment of a giant superior mesenteric artery pseudoaneurysm using a nitinol stent-graft / R. Gandini, V. Pipitone, D. Konda [et al.] // Cardiovasc. Interv. Radiol. - 2005. - Vol. 1. - P. 102-106.

7. Endovascular stent graft treatment in a patient with splenic artery aneurysm / K. Karaman, L. Onat, M. Sirvanci [et al.] // Diagn. Interv. Radiol. - 2005. - Vol. 11. - P. 119-121.

8. Hepatic artery aneurysm: factors that predict complications / M.A. Abbas, R.J. Fowl, W.M. Stone [et al.] // J. Vasc. Surg. - 2003. Vol. 38. - P. 41-45. несущей артерии. Учитывая частую локализацию АНВВ в бассейне ЧС и ВБА, предпочтительно эндоваскулярное вмешательство в связи с высоким риском интраоперационного кровотечения и разрыва.

Эндоваскулярная тактика заключается в возможности эмболизации, стентирования или эндоваскулярного протезирования. Эмболизация полости аневризмы является наиболее простым и эффективным методом лечения. Для оценки возможности выполнения эмболизации нужно учитывать характер кровотока, возможность «отключения» артерии и риск ишемии органа, коллатеральный кровоток. Цель стентирования или протезирования аневризматического мешка заключается в выключении из кровотока полости аневризмы и сохранении кровотока по артерии. Оптимальный метод эндоваскулярной коррекции, однако, не всегда доступен из-за диаметра, протяженности аневризмы и наличия необходимых устройств. Эндоваскулярное вмешательство обладает высокой эффективностью, низким процентом осложнений, является предпочтительным методом хирургического лечения АНВВ.

\section{Выводы}

Основным методом диагностики является МСКТ, которая помогает установить локализацию, оценить перспективу коллатерального кровообращения. Учитывая проведенный анализ, тактика лечения должна быть эндоваскулярной в случаях локализации АНВВ в ветвях 2 и 3 порядка висцеральных ветвей и при отсутствии возможных осложнений выключения этой артерии из кровотока. При локализации в основном стволе артерии необходима открытая хирургическая коррекция - резекция и протезирование, однако предпочтительнее эндоваскулярное протезирование. Перспективным направлением в развитии эндоваскулярных вмешательств является разработка специальных стентов и протезов для одновременного выключения и сохранения кровотока по аневризм-зависимой артерии.

\section{References}

1. Khamidov, F. F., Dibirov, M. D. \& Tereshhenko, S. A. (2013) Anevrismy visceral'nykh i pochechnykh arterij: diagnostika i lechenie [Aneurysms of the visceral and renal arteries: diagnosis and treatment]. Khirurgiya, 12, 85-88.

2. Y. L. Hiramatsu, T. Sakaguchi, T. Kawabata et al. Pancreatoduodenal artery aneurysm resulting from median arcuate ligament compression successfully treated with laparoscopic ligament section Asian. J. Endosc. Surg. 2014; 7(1): 75-78.

3. Sessa, C., Tinella, G., Porcu, P. \& et al. (2004) Treatment of visceral artery aneurysm: description of a retrospective series of 42 aneurysm in 34 patients. Ann. Vasc. Surg., 18, 695-703.

4. Janzen, R. M. \& Simpson, W. T. (2004) Visceral artery aneurysm. C. J. S., 43(4), 301-302.

5. Hossain, A., Reis, E. D., Dave, S. P. \& et al. (2001) Visceral artery aneurysms: experience in a tertiary-care center. Am. Surg., 67(5), 432-437.

6. Gandini, R., Pipitone, V., Konda, D. \& et al. (2005) Endovascular treatment of a giant superior mesenteric artery pseudoaneurysm using a nitinol stent-graft. Cardiovasc. Interv. Radiol. 1, 102-106.

7. Karaman, K., Onat, L., Sirvanci, M. \& et al. (2005) Endovascular stent graft treatment in a patient with splenic artery aneurysm. Diagn. Interv. Radiol., 11, 119-121.

8. Abbas, M. A., Fowl, R. J., Stone, W. M. \& et al. (2003) Hepatic artery aneurysm: factors that predict complications. J. Vasc. Surg., 38, 41-45.

Сведения об авторе:

Никоненко А.А., к. мед. н., доцент каф. госпитальной хирургии, Запорожский государственный медицинский университет,

E-mail: 00106@mail.ru. 